This is an electronic reprint of the original article. This reprint may differ from the original in pagination and typographic detail.

Author(s): Päivinen, Helena; Holma, Juha; Karvonen, Anu; Kykyri, Virpi-Liisa; Tsatsishvili, Valeri; Kaartinen, Jukka; Penttonen, Markku; Seikkula, Jaakko

Title: $\quad$ Affective Arousal During Blaming in Couple Therapy : Combining Analyses of Verbal Discourse and Physiological Responses in Two Case Studies

Year: $\quad 2016$

Version:

Please cite the original version:

Päivinen, H., Holma, J., Karvonen, A., Kykyri, V.-L., Tsatsishvili, V., Kaartinen, J., Penttonen, M., \& Seikkula, J. (2016). Affective Arousal During Blaming in Couple Therapy : Combining Analyses of Verbal Discourse and Physiological Responses in Two Case Studies. Contemporary Family Therapy, 38(4), 373-384.

https://doi.org/10.1007/s10591-016-9393-7

All material supplied via JYX is protected by copyright and other intellectual property rights, and duplication or sale of all or part of any of the repository collections is not permitted, except that material may be duplicated by you for your research use or educational purposes in electronic or print form. You must obtain permission for any other use. Electronic or print copies may not be offered, whether for sale or otherwise to anyone who is not an authorised user. 


\title{
AFFECTIVE AROUSAL DURING BLAMING IN COUPLE THERAPY: COMBINING ANALYSES OF VERBAL DISCOURSE AND PHYSIOLOGICAL RESPONSES IN TWO CASE STUDIES
}

\begin{abstract}
Blaming one's partner is common in couple therapy and such moral comment often evokes affective arousal. How people attune to each other as whole embodied beings is a current focus of interest in psychotherapy research. This study contributes to the literature by looking at attunement during critical moments in therapy interaction. Responses to blaming in verbal dialogue and at the level of the autonomic nervous system (ANS) were investigated in two couple therapy cases with a client couple and two therapists. Video-recorded couple therapy sessions were analyzed using discursive psychology and a narrative approach. The use of positioning, a discourse analytic tool, was also studied. ANS responses of the participants, including the therapists, were measured as electrodermal activity. The findings demonstrate how identity blaming, i.e. positioning the other person in ways counter to their preferred identity narrative, was accompanied by increased electrodermal activity in most participants. In the two cases studied, blaming centered on the themes of loyalty, trust and parenting. It is argued that identity blaming in these thematic domains increases the arousal level of the partners, since disloyalty, unfaithfulness and irresponsible parenting threaten the stability of the relationship.
\end{abstract}

Keywords: Couple therapy, discourse, narrative, positioning, autonomic nervous system, electrodermal activity 


\section{INTRODUCTION}

In couple therapy, the partners face and discuss challenging issues pertaining to their relationship. Blaming the other is typical at the beginning of joint therapy, and, even if their objective is to remain neutral, the therapists will also find themselves involved in these moral judgments (Kurri and Wahlström 2005; Rober 2015; Stancombe and White 2005). Therapist directive approach at the beginning of conjoint treatment process can be helpful in making both partners accountable (Vall et al. 2015). Blaming and resisting criticism involve emotions which may be manifested not only in the partners' verbal and non-verbal responses (Edwards 1995) but also in their responses at the level of the autonomic nervous system (ANS). The aim of this exploratory paper is to combine the levels of verbal dialogue, ANS and the inner dialogues of the participants to illuminate the experience of blaming in the couple therapy context.

Blame can be conveyed through explicit accusations or complaints (Buttny 2004), or through more implicit expressions of needs and wishes (Edwards and Potter 1995). Either way, blaming someone always contains a moral judgement. Thus, being blamed may elicit moral affects of shame and guilt. Blaming has traditionally been studied within an attributions framework (Stratton 2003). Findings from couple relationship interaction studies by the Gottman group show how criticism in conflict resolution is one of the major predictors of relationship instability (Gottman and Gottman 2008). The authors define criticism as the declaration by one partner that the conflict is attributable to a deficit in the character of the other partner. Character blaming of this kind is considered the most damaging form of blame since while changing one's behavior is possible, changing oneself as a person is less conceivable. Characterological blaming places full responsibility on the agent and targets their identity (Stratton 2003). 
From the discursive perspective applied in this study, the self is not a stable entity, but is constantly being constructed and reconstructed in social encounters (Burr 2003). The formation of identity is thus a fluid and dynamic, ever continuing process (Avdi and Georgaca 2009). Couple therapy in turn presents an institutionalized context for the construction of identity. This identity work is carried out through various discursive acts, such as ways of speaking about oneself and others. From a discursive viewpoint, casting blame is understood as constructing a questionable position for the target in the local discourse. A position is a moral place with certain rights and duties, which can be given and taken up in the course of the interaction (Davies and Harré 1990). Being assigned a position not in line with one's preferred identity narrative may be experienced as uncomfortable or troubling (Edley 2001; Wetherell 1998), and hence attempts to reposition oneself may be performed. As well as being flexible and subject to change, positioning is also relational (Harré and van Langenhove 1991). In this study, blaming is defined as the making of critical positioning statements concerning something that one of the partners did or did not do, or what kind of a person s/he is or is not.

This paper forms part of a broader research project, The Relational Mind in Events of Change in Multi-actor Therapeutic Dialogues, which aims at increasing understanding of attunement and synchrony in couple therapy at various levels, including both verbal and nonverbal interaction and ANS responses (Karvonen et al. 2016; Seikkula et al. 2015). The project is being conducted at the University of Jyvaskyla, Finland in collaboration with three other European universities. According to the dialogical perspective taken in the project, people are attuned to each other not only in their speech acts but in their whole embodied being (Bakhtin 1984). Research on embodiment in psychotherapy has previously been done, for example, at the levels of facial expressions (Bänninger-Huber 1992), nonverbal behavior (Ramseyer and Tschacher 2011), and neurobiology (Fishbane 2011). Physiological 
synchrony has been observed when negative emotions are expressed in high conflict exchanges between dissatisfied couples (Levenson and Gottman 1983). On the other hand, synchrony has been linked to empathy between client and therapist (Marci et al. 2007). Recently however, Karvonen et al. (2016) found the strongest sympathetic synchrony in the therapist dyad in a multiactor couple therapy setting. The authors speculated that this finding was related to the training and position of the therapists in the therapy situation. To our knowledge, Relational Mind is the first research project to use a naturalistic couple therapy design with two clients and two therapists to study attunement at multiple levels (Seikkula et al. 2015).

Currently, efforts are being made to extend qualitative analysis by measuring the embodied aspects of dialogue (Cromby 2012; Lyons and Cromby 2010; Author citation 2015). Here, the embodied level is approached by measuring the electrodermal activity (EDA) of the participants. EDA refers to changes in skin conductance (SC) that are connected to involuntary changes in sympathetic nervous system activity, which in turn prepare the body for action (Boucsein 2012). Generally, SC indicates psychophysiological arousal, which is linked to psychological processes. An increase in EDA suggests emotional arousal, since most emotions induce an increase in SC (Kreibig 2010). However, cognitive work, movement and rapid changes in respiration may also effect changes in SC (Boucsein 2012). Moreover, orienting and attention may include SC arousal. Taking into account the uncertainties in interpreting EDA arousal, the present study is an exploratory attempt to increase understanding of the experience of blaming in couple therapy. Our hypothesis is that blaming in couple therapy involves affective arousal on the level of the ANS, and hence we ask the following research questions:

1. How do the partners position each other when casting blame in couple therapy? In what ways are the therapists involved in this discursive process? 
2. What responses are evoked at the levels of verbal dialogue and EDA by all the participants during blaming?

\section{METHODS}

\section{Design}

In the Relational Mind project, couple therapy is conducted and studied with couples who have sought therapy for various reasons. The Ethical Board of the University of Jyvaskyla approved the research and the participants gave their written informed consent. The therapy sessions are run by a co-therapist dyad and the treatment is non-manualized. Various modes of therapy - e.g. dialogical, narrative and reflective - are used. All the sessions are video-recorded. Each participant's ANS measurements (SC, respiration and heart rate) are recorded during the second and the fifth to seventh therapy sessions. A stimulated recall interview (henceforth SRI) method is applied within one day of these measurement sessions to capture participants' self-reports of their thoughts, feelings and sensations. Both the two clients and the two therapists are interviewed in turn. These individual interviews center on four video clips of important moments during the measurement session selected by the researcher. A sequence can be considered important on the basis of the topic or passages of dialogue, visible emotion or observed signs of ANS arousal. The same physiological measurements, along with finger pulse volume and speech muscle movements, are also recorded. The interviewed are asked about the thoughts/feelings/bodily sensations they had at that moment in the therapy session. After all four extracts have been discussed about, the interviewer asks the interviewed had selected some other moment which she/he would have wanted to see today. If the participant names some moment the thoughts/feelings/bodily sensations that the participant recalls from that moment are discussed. 
The cases

The two cases analyzed for this report were drawn from the ten couples receiving therapy in the Relational Mind project. These two couples were selected since intimate partner violence (henceforth IPV) was one of the reasons for their seeking therapy. This selection was also made to facilitate possible future comparisons with couples whose histories do not include IPV. However, in this particular study, no such comparisons were made, nor were the findings generalized to all IPV couples. In the Relational Mind project, joint therapy with IPV couples is only started if the IPV has been mild to moderate and has ended. Both partners have to be willing to attend the therapy meetings and be able to speak openly in them. The partners in both couples had previously attended individual meetings at the local crisis center. Two of the present authors were working as therapists in these cases and two other therapists were also involved. All the therapists were experienced psychotherapists specializing in family therapy.

Case 1 was a heterosexual couple, Heli and Lasse (pseudonyms), with children. Heli was pregnant at the time of the measurement session. They were attending couple therapy owing to relationship problems and Lasse's violent behavior. Lasse had been physically violent towards Heli, the most serious instance of which had been attempted strangulation. Even if this instance of violence had been severe, both partners wished to have couple therapy, felt that they can speak openly in conjoint session, and wanted to continue their relationship. For these reasons and after Lasse having attended long term individual IPV treatment, this couple had been included in couple therapy for IPV. Their course of therapy lasted for 10 sessions. A male-male therapist dyad (T1, T2) worked with this couple. The same case has also been studied by others in the project (Itävuori et al. 2015; Kykyri et al. manuscript in preparation). Case 2 was a same-sex couple who had sought couple therapy for IPV. Tina and Jenny (pseudonyms) were parents of a toddler and were currently living 
separately. Jenny’s violent behavior towards Tina had included both physical (e.g. striking with the fist) and emotional forms of IPV. The therapy comprised a total of five sessions, each conducted by the same male-female therapist dyad (T3, T4).

\section{Analysis}

A multi-method qualitative analysis was performed. The spoken dialogue was analyzed using both discursive psychology (Edwards and Potter 1992, Potter 2003; 2012) and narrative approach (Avdi and Georgaca 2007; McLeod 1997, 2004). From the viewpoint of discursive psychology, blaming was conceptualized as a speech act of positioning that ascribes moral responsibility to the target (Davies and Harré 1990). The narrative approach, in turn, adds the temporal and contextual elements into the analysis of the blaming sequences (Sarbin 1986). In other words, the flow and evolution of the themes around which the blaming forms, were rendered more visible. The methodological concept of micro narrative (Bamberg 1997; Kraus 2006) was developed and tested in this analysis to link the blaming sequences in the flow of the therapy session. Basically, in the therapy dialogue, a micro narrative is a story line that forms around a particular theme.

The analysis was started by the first author viewing all the videotaped therapy sessions featuring the two couples to gain an overall picture of the cases and what was talked about in the sessions. In each case, the data for the study were restricted to the second therapy session, as this was the first measurement session in the project design. Blaming was chosen as the unit of analysis for defining and selecting the sequences of the therapy conversation to be taken for further analysis. A blaming sequence in the therapy session was defined as a sequence of dialogue in which one of the partners is explicitly positioned as responsible for doing or not doing something, or being or not being something. The blaming sequences were classified thematically and the blaming dialogue around a specific theme was written up as a 
micro narrative. The blaming themes and micro narratives were identified by the first and second author for triangulating the findings.

EDA was measured from the palm of the participants' non-dominant hand, using two electrodes. The EDA of all four participants was examined visually from the raw SC data during the instances of blaming. SC responses were also detected using the Ledalab program (Benedek and Kaernbach 2010). The signals were standardized for each participant. The raw skin conductance recordings were decomposed into skin conductance responses (SCR) and skin conductance level (SCL) using continuous deconvolution analysis (Benedek and Kaernbach 2010). In the same paper, it is suggested that SCR is directly linked to the sympathetic activity and it was therefore selected for further analysis. The extracted SCRs were standardized and peak detection was applied. Peaks that were two or more standard deviations above the mean were selected as statistically significant SCRs. These statistical procedures were carried out by the fifth and seventh authors.

The micro narratives along with the EDA responses were studied, first, by the first author and the results then negotiated with the second author. Together, they identified which sequences of the blaming micro narratives were accompanied by an increase in the level of arousal, i.e., an observable increase in the raw EDA, and later incorporated the calculated statistically significant SCRs into the analysis. The micro narratives and blaming sequences found were subsequently confirmed by the research group. Finally, the participants' thoughts, emotions, and sensations, self-reported in the SRIs, were used as information to gain insight into the observed physiological arousal. Since blaming was not the criterion for the selection of the video clips in the SRIs, this additional information was only available for some parts of the blaming micro narratives.

\section{FINDINGS}


The three blaming micro narratives drawn from the two cases are presented along with the participants' EDA responses. The instances of blaming, i.e. moments in a session when a blaming incident occurred, are given in brackets (hours: minutes: seconds). The findings from the SRI's are presented after each micro narrative. The observed changes in EDA are shown in figures (figures 1, 2, and 3) and statistically significant SCR activity in each participant during an instance of blaming is presented in a table (tables 1, 2, and 3) after each figure.

\section{CASE 1: The micro narrative of loyalty.}

The theme of loyalty, disentangling from one’s family of origin and forming the new family together with one's partner, constituted a blaming micro narrative in couple 1's therapy dialogue. Commitment as a partner and a parent was linked to this micro narrative. In this micro narrative, Heli blamed Lasse for not being on her and their family’s side, thereby positioning him as being loyal to his family of origin instead of to his new family with her.

The micro narrative begins when the couple describe an argument in which Lasse had taken his sister's side instead of supporting Heli. About ten minutes later, T1 asks Heli whose view Lasse shares: hers or his sister's (time 1, 00:17:09). Heli shows SCR activity and her EDA remains elevated when she explains how Lasse takes the side of his family of origin. With this utterance, Heli positions Lasse as not committed to their joint family. At the moment of this positioning, Lasse's EDA does not rise. T1 shows a rise in EDA before he asks for Heli’s view. In T2, EDA decreases.

T1 shows high EDA before he next asks the couple to evaluate themselves as a team. During T1's question (time 2, 00:21:27), EDA increases in both clients, and, as they tell and listen to each other's evaluations, both also show SCR activation. In T2, EDA falls. Three minutes later, the therapists together reflect on the reasons for Lasse's loyalty to his family of origin. Lasse describes his relationship to his family of origin when requested by T1. Heli 
listens to Lasse's account and then, as she explicitly points out that Lasse is not ready to risk his relationship with the most important family members of his family of origin (time 3, 00:34:11), shows SCR activation. In blaming Lasse in this way, Heli clearly positions him as a member of his family of origin. Lasse’s EDA manifests no obvious changes. T1 shows an increase in EDA. T2 shows no clear EDA response.

About eight minutes later, T2 asks Heli if she could somehow help Lasse to choose her side in conflict situations. Heli points out that when it comes to the children alarm bells should ring for Lasse about which side to choose (time 4, 00:46:59). Here, when explicitly blaming Lasse as a father, Heli shows SCR activation. Lasse’s EDA in turn remains unchanged. As T2 asks this question, his EDA begins to rise and his SCR activation shows two peaks during Heli’s account. In T1, EDA shows no change.

Fourteen minutes later, T2 reflects on the couple's situation and the loyalty theme. During his reflections, T2 shows a rise in EDA rises and Lasse, Heli and T1 show SCR activation (time 5, 01:01:41). The discussion then turns to Lasse's loss of his grandmother and his sorrow over her passing. Lasse is visibly moved during this discussion. In this discussion, Lasse is positioned as a member of his family of origin. T1 asks Heli how she feels when Lasse reflects aloud on his feelings of longing. Heli answers (time 6, 01:12:11): “Yeah, it’s difficult to say. You somehow wish like that like I can’t say, I thought that Lasse is anyway like a grownup man and a father even though like the like the what how do you call the family there the family of origin or the like (...) That even though it is like in a big role and important like someway that he could see that like life is anyway at this moment like with us, we are like a nuclear family” Besides seeing Lasse as a member of his family of origin, Heli also positions him as an adult, partner and father, and by expressing her wish she blames Lasse for not taking up this position. Heli again shows SCR activation. Lasse shows increased EDA during the discussion 
about his loss, and now also SCR activation. The video shows that Lasse also touches and scratches his face while listening to Heli. In T2, EDA peaks and he also shows SCR activation. In T1, in contrast, EDA decreases.

In summary, Heli manifested SCR activation each time that she blamed Lasse for not being loyal to their family and not taking up the position she offered him as a partner and a father in the family. Lasse responded to Heli's blame only at the end of the session when she explicitly targeted his identity and strong emotions were involved. At that point, one of the therapists also showed high EDA.

\section{Stimulated recall interviews}

In the SRIs, two of the four clips covered the discussion on Lasse's sorrow over his late grandmother (before and after time 6). In their individual SRIs, both Lasse and T2 reported having felt a strong sense of longing at this moment in the session. In her SRI, Heli reported having felt sorrow but also insensitivity to her partner's grief. In his SRI, T1 stated that he did not relate to Lasse’s sorrow.

Fig. 1 Raw EDA of the participants over the entire session of couple 1. Range is scaled separately for each participant. The vertical lines indicate the instances of blaming in the micro narrative of loyalty

[Fig. 1 should be placed here]

Table 1 Case 1, loyalty: SCR activation of each participant during blaming [Table 1 should be placed here]

CASE 2: The micro narrative of parenting. 
Responsible parenting was at the center of one of the two blaming micro narratives of couple 2. This micro narrative was also linked to a loyalty conflict between the family of origin and the current family. First, Jenny blamed Tina (the birth mother) for her way of parenting; later Tina accused Jenny of not taking responsibility as parent. Thus Tina positioned Jenny as an irresponsible parent.

The blaming micro narrative begins when Jenny criticizes Tina for complying too much with her parents' wishes. She accuses Tina of not listening to her opinion in these situations. Tina's family relations are explored by the therapists and she explains her behavior by reference to her motherhood. During this talk, Jenny shows a gradual rise in EDA and on two occasions she verbally challenges Tina's account. Jenny shows SCR activation when she explicitly accuses Tina of keeping up relationships that are hurtful to her and thus also to their child (time 1, 00:29:06). With this accusation, Jenny positions Tina as a parent but further questions Tina’s parenting, how Tina acts as parent. Tina shows a rise in EDA when she is positioned in this way, along with SCR activation when she starts to justify her behavior. The therapists show no EDA response to Jenny's positioning of Tina.

Soon after, Tina describes how Jenny does not take as much responsibility for their child as she does. By accusing Jenny of being irresponsible, Tina questions Jenny’s position as a parent. Tina shows SCR activation when she blames Jenny for irresponsibility (time 2, 00:30:43). EDA remains elevated in Jenny and also shows an increase in the therapists. Tina’s positioning of Jenny is underscored by T4, who restates Tina's view that she is bearing all the responsibility for the child. T4 shows SCR activation when she verbally echoes Tina's words.

Five minutes later, T4 asks Jenny what she thinks about Tina being burdened by the partners' unequal distribution of responsibilities in parenting (time 3, 00:45:31). In putting this question, T4 is following Tina's positioning of Jenny as an irresponsible parent, and her 
SCR peaks. Jenny manifests SCR activation when presented with T4's question, as also does Tina as Jenny answers it. Tina also becomes tearful. SCR activation is also apparent in T3. Jenny accepts being positioned as an irresponsible parent by saying that she agrees that the situation isn't right. Jenny then justifies her irresponsibility by saying that she is neither able nor willing to give ground. Tina voices her doubts about Jenny’s parenting again (time 4, 00:47:24) during which her SCR peaks. EDA in Jenny continues to fall. In the therapists, EDA also declines.

Next, T3 asks Tina how the couple share Mother's and Father's Day (time 5, 00:50:12). Tina has mentioned Mother’s Day a little earlier and in posing this question, T3 is confirming Tina's position as the primary mother of the child. Jenny shows SCR activation. SCR is also activated in T3 when raising the topic and remains elevated while the topic is discussed. In T4, EDA falls. Tina manifests a smaller increase in EDA and she describes their gender roles, positioning Jenny as the more masculine and herself as the more feminine partner. In Jenny SCR activation is visible once again peaking when Tina positions her as an irresponsible male by saying (time 6, 00:51:18):

“Jenny even looks like a twelve-year-old little boy...”

Tina also shows SCR activation. Here, Tina also laughs a little and Jenny smiles and scratches her forehead. In T3, EDA is high. In T4, EDA is falling.

In summary, blaming that questioned Jenny’s identity as a responsible parent was accompanied by SCR activation in both clients and in one of the therapists. Linking her parenting to gender identity was also accompanied by SCR activation in both clients.

\section{Stimulated recall interviews}

The sequence in which the unequal distribution of responsibilities in parenting was talked about (time 3) belonged to one of the sequences shown to the participants in their SRIs. All 
the participants reported emotional arousal in their individual SRIs. Jenny said that she felt ashamed and thought of herself as a bad person. Tina reported having felt frustrated and apprehensive. T3 reported having felt involved and curious. T4 said she felt sad for Tina's sake.

Another sequence shown in the SRIs concerned the gender roles of the couple (Time 5 and time 6). Jenny did not comment on this topic at all. Tina said that the theme of gender roles is one that she is used to discussing with people. T3 says that he had to think how to ask the question and that he felt apprehensive about how the question would be received. T4 says that she was surprised but felt happy about the raising of this topic.

Fig. 2 Raw EDA of the participants over the entire session of couple 2. Range is scaled separately for each participant. The vertical lines indicate the instances of blaming in the micro narrative of parenting

[Fig. 2 should be placed here]

Table 2 Case 2, parenting: SCR activation of each participant during blaming [Table 2 should be placed here]

CASE 2: The micro narrative of trust.

Another blaming micro narrative in the therapy session of couple 2 centered on trust and commitment. Jenny had had an affair and had also been unfaithful in her previous relationship. In this micro narrative Tina positioned Jenny as an uncommitted partner; this Jenny did not accept.

Immediately after the parenting theme, T4 asks Tina what it meant for her to hear about Jenny having been unfaithful in her previous relationship. This topic had initially been 
brought up in the previous session. Both clients manifest SCR activation simultaneously when T4 finishes the question (time 1, 00:52:48). In T4, EDA is high when she asks the question, whereas in T3 EDA falls.

Jenny's infidelity is discussed and T3 focuses on how it has affected trust between the couple. Tina describes how Jenny’s cheating has affected their relationship, and thus blames Jenny for causing problems of trust (time 2, 00:54:58). In this way, Tina positions Jenny as an unfaithful and uncommitted partner. Jenny and T3 show SCR activation. Tina continues describing how uncertainty about Jenny's commitment makes her feel like an independent single parent. By positioning herself in this way, Tina connects the micro narrative of trust to the micro narrative of parenting. T4 asks Jenny about her commitment, and Jenny answers that she can see that in Tina's eyes she is untrustworthy, yet she is sure that she wants to stay in her relationship with Tina. By this means, Jenny repositions herself as committed.

However, Tina again brings up her doubts about Jenny’s commitment. Both the clients and therapists show a slight increase in EDA (time 3, 00:59:08). Jenny, who is blamed, shows SCR activation. She also touches her face at this point. T4 asks Tina what she thinks Jenny could do to ease this uncertainty. Tina describes how Jenny has not announced their reconciliation to her relatives (time 4, 01:03:29). Tina shows SCR activation as she elaborates this issue, positioning Jenny as uncommitted. In Jenny at this point, EDA is already falling and neither of the therapists show any EDA responses. Finally, Jenny accepts that, as Tina wishes, she has to tell her family about their relationship.

In summary, bringing up the theme of infidelity was accompanied by simultaneous SCR activation in both clients and in the therapist taking the lead. This topic, which threatened the couple's relationship, brought Jenny's partner identity into question and, when the direct target of identity blame, she showed SCR activation. 


\section{Stimulated recall interview}

The sequence in which T2 brought up the topic of infidelity (time 1) was shown in the individual SRIs. In her SRI, Tina reported that this topic raised no emotions in her since she sees Jenny’s previous cheating as an issue that she will never understand. Jenny, in her interview, said that she had not wanted to talk about this topic, as it had made her feel embarrassed, uneasy and tense in the session. In their individual SRIs, both therapists reported having had many thoughts about the topic and the therapy process.

The discussion about announcing the relationship to the larger family (after time 4) was also shown in the SRIs. Jenny said she felt uncomfortable about the topic and irritated by being assigned this task by Tina. Tina reported having felt sad, and in their interviews both therapists report having felt empathy for Tina and her sadness.

Fig. 3 Raw EDA of the participants across the entire session of couple 2. Range is scaled separately for each participant. The vertical lines indicate the instances of blaming in the micro narrative of trust

[Fig. 3 here]

Table 3 Case 2, trust: SCR activation of each participant during blaming [Table 3 should be placed here]

\section{DISCUSSION}

In this study, we examined the positioning of one partner by the other in instances of blaming in couple therapy, showing how blaming evolves during the session, and involves physiological responses on the part of both client and therapist. Drawing together the results of the two case studies, our main finding is that blame, especially when targeted at the 
partner's identity, was accompanied by SCR activation both in the clients and also, on some occasions, one of the therapists. We would argue that in couple therapy such identity blaming is an instance of troubled positioning, as is shown by affective arousal in the target. We propose that identity blaming around certain themes may also be arousing for other participants than the target alone since the stability of the relationship is at risk. This paper aimed at developing a methodology for investigating and treating these situations by combining language-based analysis and physiological measures. Below, the meaning, implications and limitations of the findings of this exploratory paper are discussed.

From the discursive viewpoint, identity is constructed via the various positions we take up and are offered in social interactions (Davies and Harré 1990). Not all positions feel fitting or acceptable as part of one’s identity (Edley 2001; Wetherell 1998). Blaming, criticizing or even commenting on one's partner as a person in a neutral tone may construct a position that is troubling for them and challenges their preferred identity narrative. The findings of this study demonstrate how troubled positioning is accompanied by affective arousal in the blamer, the blamed, and in those who are witnessing the attribution of blame. It was further shown that in couple therapy troubled positioning is constructed around such themes as loyalty, parenting and trust.

These blame-ascribing micro narrative themes concerned central issues that people face and have to negotiate in their intimate relationships when contemplating becoming or forming a family. These themes also relate to responsibility, safety and trust, which have been considered the main goals of conjoint IPV treatment (Vall et al. 2014). To begin with, the theme of loyalty involves setting boundaries, which is a basic task for any new family (Minuchin 1974). For couple 1, this task had become a loyalty issue that involved blaming. This theme, and the blame it gave rise to, was present throughout their one-and-a-half-hour session. The theme of loyalty was more arousing for Heli, in whom SCR activation was 
present when she was blaming her partner. Lasse in turn manifested SCR activation when Heli explicitly questioned his identity as an adult father in their family. In T2, EDA became elevated at this point. Bearing in mind the context of a history of IPV, it can be hypothesized that blame targeted at one's partner on a familiar topic may remind the partners of the incidents of violence and activate the sympathetic nervous system.

Furthermore, in both cases, the blaming micro narratives were intertwined with parenting. Parenting, and the new responsibilities that come with it, adds to the necessity and possibilities for positioning in the couple relationship. Parenting also means building a new component into one's identity. In couple treatment for IPV, parenting is a central theme, as it has been shown that being a parent may furnish perpetrators with a strong motivation to take responsibility and work to change their violent behavior (Cooper and Vetere 2005; Råkil 2006; Veteläinen et al. 2013). For couple 1, parenting was part of the broader loyalty issue. Couple 2, in turn, was explicitly negotiating the responsibilities of parenting. SCR peaked in Jenny when Tina portrayed her as a little boy, i.e., Tina’s blame encompassed Jenny’s identity as a responsible parent, female and adult. SCR activation was also observed in T1 and Tina at this point. For both couples, parenting was linked to the target's gender identity. Parenting places partners in new, unequal positions, as they now have to negotiate their caregiving responsibilities (Ciano-Boyce and Shelley-Sireci 2002). For same-sex couples this negotiation also means that one of the partners fails to fulfil yet another of society's normative gender expectations (Ciano-Boyce and Shelley-Sireci 2002; Mazor, 2004).

Finally, for couple 2, a micro narrative of blaming on the theme of trust was introduced towards the end of their session. Security, intimacy and trust are generally considered the basis of love relationships. Violence and infidelity challenge this basic premise and may damage the attachment of the injured partner (Johnson et al. 2001). It is possible that such damage leads to the enactment of a negative blame-withdraw cycle that pulls the couple 
further apart and thus puts the stability of the relationship at risk (Gottman and Gottman 2008). In the case of couple 2, Jenny was positioned as unfaithful, and thus her partner identity was questioned. She showed SCR activation when blamed and in her SRI she stated that this theme was something she didn’t want to talk about in the therapy session and that she found it embarrassing. Visual observation of the raw EDA data showed that all present seemed to have an increased level of arousal during the discussion on this theme. The therapists also defined this theme as important and thought-provoking in their SRIs.

In each theme, the therapists were closely involved in the construction of the client micro narratives of blame. By means of, for example, questions and voiced reflections the therapists validated and took some of the attributions of blame further and thus participated in the moral negotiations of the couples. Their participation indicated that the therapists found the themes of the micro narratives of blame important for the therapy process. This was evident in their SRIs, where the therapists explicitly evaluated the topics of the micro narratives as important, and also reported on the evoking of emotions.

The therapists often showed opposed EDA responses during the clients' identity blaming. We propose that this may be due to the therapists at times following different story lines, engagement in diverse conversational tasks or experiencing empathy for different clients. Earlier research on couple treatment for IPV has found that the clients, both women and men, appreciate having male-female co-therapists (Lechtenberg et al. 2015). It would be interesting to study how the gender of the therapists might impact the quality of therapeutic alliance and consequently their physiological responses. However, the data of this study is limited for such research. Also, in the findings of this paper, therapists of same gender respond differently to blaming. For example, the two male therapists working with couple 1 mentioned in their individual SRIs that important issues were talked about in the clips shown; however, they saw and felt the situation in different ways, which could explain the 
differences in their EDA responses. Differences in the agendas and tasks of the therapists in this particular case have been studied in another paper in the Relational Mind project (Kykyri et al. manuscript in preparation). Along with Seikkula et al. (2015), we suggest that variation in synchrony may be a positive phenomenon in a multiactor therapy setting in that more perspectives are taken into consideration.

In the cases studied, blame was mainly cast by the same partner. During identity blaming, the target, who did not necessarily respond to other types of blame, showed SCR activation. At the same time, the therapists showed affective EDA. This finding is in line with Levenson and Gottman (1983), who reported the highest levels of physiological linkage during the expression of emotions by distressed couples in conflict discussions. For example, in case 1, in which Lasse's identity was the target, the SCR that accompanied Heli's criticism was framed by strong emotions of longing and sadness. It may be argued that this kind of an emotional atmosphere renders the attribution of blame even more effective. Moreover, Heli's blaming utterance was explicitly targeted towards Lasse’s identity as a man and a father. Closer scrutiny of the SRIs revealed that the participants did in fact report opposition and emotional arousal during some of the identity blaming sequences. Furthermore, the therapist's physiological responding when witnessing clients' blaming highlight an important aspect of couple therapy: namely the viewpoint of the children. Based on the findings of this study it can be suggested that like the therapists when listening to their clients' blaming, also children who witness their parents' conflicts, respond physiologically in these situations. Being exposed to parental violence has been linked to trauma symptoms including emotional and behavioral problems in children (Evans et al. 2008; Wolfe et al. 2003). Hence, developing treatment for children who are exposed to violence should also focus on physiological responses. 
Nevertheless, drawing any firm conclusion about the stimuli evoking parallel SCR activation is complicated. In addition to the emotional value of the blame content, other factors may be linked to EDA arousal (Boucsein 2012). Movements by the participants can increase their level of arousal, and such movements were indeed observed in the videorecordings during some blaming moments. However, preparing to act causes the level of arousal to rise before the actual body movement (Burgoon et al. 1989). Self-touching has also been linked to emotion regulation (Grunwald et al. 2014; Ekman and Friesen 1969), and thus observations of hand movements may rather enrich the analysis than interfere with the findings. However, a more detailed analysis of attunement in body movements is beyond the scope of this study and is left for future research. Also, orienting responses and cognitive effort in, e.g., preparing one’s utterance may include affective arousal. Some themes were raised by asking a direct question or making a comment. It should also be mentioned that SCRs were not activated only during blaming but were also observed in each participant outside of the blaming micro narratives.

In both the cases studied, blaming one's partner was done in particular by the victim of the IPV. Blaming that targeted the abusive partner was in most cases accompanied by SCR activation in the accuser, possibly suggesting activation of the flight-or-fight response caused by fear or uncertainty over the perpetrator's reaction. However, the possible links between arousal and IPV are hypothetical in this study, since no comparison with couples with no history of IPV was conducted. Blaming the other is a sensitive issue and may also be accompanied by emotional arousal in couples with no history of IPV. Implications for practice

This paper argues that when targeting the other person's identity, blaming is a strong discursive act which also shows at the level of the ANS. The findings of this study draw attention to more implicit and subtle blaming, the moral load of which becomes visible only 
when the utterance is placed in the context of the blaming micro narrative as a whole. Commenting on the other person's identity may be a cue for the therapist to expect blaming. Paying attention to comments of this kind about the other person present may help the therapist in addressing serious criticism. Reformulating identity blaming to target behavior instead of the person may work as an intervention in couple therapy. In the Gottman couple therapy model, blame is reformulated as a positive, contextualized wish for a change in one's partner’s behavior (Gottman and Gottman 2008).

Furthermore, the findings highlight the embodied aspects of therapeutic interaction. Reciprocal physiological responses have been seen as part of transference countertransference processes (Schore 2001; Schore \& Schore, 2007). Paying attention to and noticing physiological changes in clients or in oneself may signal to the therapist that something emotional or important is going on. Such signals can be brought up in the verbal dialogue and may benefit clients’ learning by soothing their affective arousal (Gottman and Gottman 2008; Greenberg and Goldman 2008). Recognizing physiological changes in oneself may increase therapist reflexivity, and such observations should be encouraged and addressed also in supervision.

\section{Limitations of the study}

In this study, a qualitative methodology was developed which combines discursive psychological and narrative ideas. The aim was to contribute to understanding how interaction takes place on different levels in couple therapy. The limitations of the qualitative reading include lack of dual coding in the initial phase of the analysis. However, researcher triangulation was used when selecting the most explicit blaming sequences and in writing micro narratives around these blames. Moreover, the intention of the present case study is not to make general assumptions about responses to blaming. Any such endeavor would require larger data, whereas the aim of this study was rather to investigate some aspects of blaming 
dialogue. Also, the aim of this study was not to compare couples with a history of IPV and couples with no such history. Data were selected with an eye to the possibility of such comparative research in the future. Finally, the use of EDA as the only physiological measure of affective arousal is a limitation of this study. To tackle the problem caused by the possible links between EDA arousal and multiple stimuli, the analysis was supplemented with the use of SRIs. However, the SRIs did not cover all the blame sequences, and hence the participants' reports have to be interpreted in their context, which is not the same as the actual therapy interaction. Identifying the affective arousal during therapy conversations could be further enhanced by analyzing nonverbal behavior, e.g. gaze and facial expressions (Patterson et al. 2012).

\section{Future research}

An important question for future research is the evolution of blame in the course of the couple therapy process at both the verbal and embodied levels. A fuller understanding of positioning and identity work in couple treatment would require combining multiple sources of ANS and nonverbal interaction with qualitative analysis. However, based on this analysis we would highlight the importance of the embodied aspects of therapeutic interaction. The analytic choices made in this study may prompt future research on the value of physiological data in understanding interaction phenomena. Furthermore, the analysis demonstrated the clinical value of discursive analysis. The findings encourage clinicians to intervene in comments and criticisms targeting the other's identity and which may include attributions of blame.

Conflict of Interest: The authors declare that they have no conflict of interest. 


\section{REFERENCES}

Avdi, E., \& Georgaca, E. (2007). Narrative research in psychotherapy: A critical review. Psychology and Psychotherapy: Theory, Research and Practice, 80(3), 407-419. doi:10.1348/147608306X158092

Avdi, E., \& Georgaca, E. (2009). Narrative and discursive approaches to the analysis of subjectivity in psychotherapy. Social and Personality Psychology Compass, 3, 654-670. doi:10.1111/j.1751-9004.2009.00196.x

Bakhtin, M. (1984). Problems of Dostojevskij's poetics: Theory and history of literature (Vol. 8). Manchester, England: Manchester University Press.

Bamberg, M. G. W. (1997). Positioning between structure and performance. Journal of narrative and life history, 7, 335-342. Retrieved from http://www2.clarku.edu/ mbamberg/Papers/Positioning\%20Between\%20Structure\%20 and\%20Performance.pdf

Benedek, M., \& Kaernbach, C. (2010). A continuous measure of phasic electrodermal activity. Journal of Neuroscience Methods, 190, 80-91.

doi:10.1016/j.jneumeth.2010.04.028

Boucsein, W. (2012). Electrodermal activity. Boston: Springer.

Burgoon, J. K., Kelley, D. L., Newton, D. A., \& Keeley-Dyreson, M. P. (1989). The nature of arousal and nonverbal indices. Human Communication Research, 16 (2), 217-255. doi:10.1111/j.1468-2958.1989.tb00210.x

Burr, V. (2003). Social constructionism. 2nd edition. London: Routledge.

Buttny, R. (2004). Talking problems: Studies of discursive construction. Albany, NY, USA: State University of New York Press.

Bänninger-Huber, E. (1992). Prototypical affective microsequences in psychotherapeutic interaction. Psychotherapy Research, 2, 291-306. doi:10.1080/10503309212331333044 
Ciano-Boyce, C., \& Shelley-Sireci, L. (2003). Who is mommy tonight: Lesbian parenting issues. Journal of Homosexuality, 43, 1-13. doi:10.1300/J082v43n02_01

Cooper, J., \& Vetere, A. (2005). Domestic violence and family safety. A systemic approach to working with violence in families. London and Philadelphia: Whurr publishers.

Cromby, J. (2012). Feeling the way: Qualitative clinical research and the affective turn. Qualitative Research in Psychology, 9, 88-98. doi:10.1080/14780887.2012.630831

Davies, B., \& Harré, R. (1990). Positioning: The discursive production of selves. Journal of the Theory of Social Behaviour, 20, 43-63. doi:10.1111/j.1468-5914.1990.tb00174.x

Edley, N. (2001). Analysing masculinity: interpretative repertoires, ideological dilemmas, and subject positions. In M. Wetherell, S. Taylor and S. Yates (Eds.) Discourse as data: A guide for analysis (pp. 189-228). London, Sage.

Edwards, D. (1995). Two to tango: Script formulations, dispositions, and rhetorical symmetry in relationship troubles talk. Research on Language and Social Interaction, 28, 319350. doi:10.1207/s15327973rlsi2804_1

Edwards, D., \& Potter, J. (1992). Discursive psychology. London: Sage.

Edwards, D., \& Potter, J. (1995). Attribution. In R. Harré, \& P. Stearns (Eds.), Discursive psychology in practice (pp. 87-119). London: Sage.

Ekman, P., Friesen, W.V. (1969). The repertoire of nonverbal behavior: categories, origins, usage, and coding. Semiotica, 1, 49-98. Retrieved from http://boccignone.di.unimi.it/CompAff2011_files/EkmanFriesenSemiotica.pdf

Evans, S. E., Davies, C., \& DiLillo, D. (2008). Exposure to domestic violence: A metaanalysis of child and adolescent outcomes. Aggression and Violent Behavior, 13(2), 131-140. doi:10.1016/j.avb.2008.02.005

Fishbane, M. (2011). Facilitating relational empowerment in couple therapy. Family Process, 50, 337-352. doi:10.1111/j.1545-5300.2011.01364.x 
Gottman, J. M., \& Gottman, J. S. (2008). Gottman method couple therapy. In A. S. Gurman, (Ed.), Clinical handbook of couple therapy (pp. 138.164). New York: The Guilford Press.

Greenberg, L. S., \& Goldman, R. N. (2008). Emotion-focused coupes therapy: The dynamics of emotion, love, and power. Washington, DC: American Psychological Association.

Grunwald, M., Weiss, T., Mueller, S., \& Rall, L. (2014). EEG changes caused by spontaneous facial self-touch may represent emotion regulating processes and working memory maintenance. Brain Research, 1557, 111-126.

doi:10.1016/j.brainres.2014.02.002

Harré, R., \& van Langenhove, L. (1991). Varieties of positioning. Journal of the Theory of Social Behaviour, 21, 393-407. doi:10.1111/j.1468-5914.1991.tb00203.x

Itävuori, S., Korvela, E., Karvonen, A., Penttonen, M., Kaartinen, J., Kykyri, V. L., \& Seikkula, J. (2015). The significance of silent moments in creating words for the notyet-spoken experiences in threat of divorce. Psychology, 6(11), 1360-1372. doi:10.4236/psych.2015.611133.

Johnson, S. M., Makinen, J. A., \& Millikin, J. W. (2001). Attachment injuries in couple relationships: A new perspective on impasses in couples therapy. Journal of Marital and Family Therapy, 27, 145-155. doi:10.1111/j.1752-0606.2001.tb01152.x

Karvonen, A., Kykyri, V. L., Kaartinen, J., Penttonen, M., \& Seikkula, J. (2016). Sympathetic nervous system synchrony in couple therapy. Journal of Marital and Family Therapy, 42(3), 383-395. doi:10.1111/jmft.12152.

Kraus, W. (2006). The narrative negotiation of identity and belonging. Narrative Inquiry, 16, 103-111. doi:10.1075/ni.16.1.14kra

Kreibig, S. D. (2010). Autonomic nervous system activity in emotion: A review. Biological Psychology, 84(3), 394-421. doi:10.1016/j.biopsycho.2010.03.010 
Kurri, K., \& Wahlström, J. (2005). Placement of responsibility and moral reasoning in couple therapy. Journal of Family Therapy, 27, 352-369. doi:10.1111/j.14676427.2005.00327.x

Kykyri, V. L., Karvonen, A., Nyman-Salonen, P., Kurri, K., \& Wahlström, J. Changes in participants’ affiliation, bodily synchrony and attunement while handling of allegiance problem in couple therapy—a mixed method case study (manuscript in preparation).

Lechtenberg, M., Stith, S., Horst, K., Mendez, M., Minner, J., Dominguez, M., Hughes, V., \& McCollum, E. (2015). Gender differences in experiences with couples treatment for IPV. Contemporary Family Therapy, 37(2), 89-100. doi:10.1007/s10591-015-9328-8

Levenson, R. W., \& Gottman, J. M. (1983). Marital interaction: Physiological linkage and affective exchange. Journal of Personality and Social Psychology, 45(3), 587-597. doi:10.1037//0022-3514.45.3.587

Lyons, A. C., \& Cromby, J. (2010). Social psychology and the empirical body: Rethinking the relationship. Social and Personality Psychology Compass, 4, 1-13. doi:10.1111/j.1751-9004.2009.00219.x

Marci, C. D., Ham, J., Moran, E., \& Orr, S. P. (2007). Physiologic correlates of perceived therapist empathy and social-emotional process during psychotherapy. The Journal of Nervous and Mental Disease, 195, 103-111. doi:10.1097/01.nmd.0000253731.71025.fc

Mazor, A. (2004). Same-gender couple therapy: Creating new objects in intimacy and parenehood transition. Contemporary Family Therapy, 26(4), 409-423. doi:10.1007/s10591-004-0644-7

McLeod, J. (1997). Narrative and psychotherapy. London: Sage.

McLeod, J. (2004). Social construction, narrative, and psychotherapy. In L. E. Angus, \& J. McLeod (Eds.), The handbook of narrative and psychotherapy: Practice, theory, and research (pp. 351-365). London: Sage. 
Minuchin, S. (1974). Families and family therapy. London and New York: Routledge.

Patterson, J., Gardner, B. C., Burr, B. K., Hubler, D. S., \& Roberts, K. M. (2012). Nonverbal Behavioral Indicators of Negative Affect in Couple Interaction. Contemporary Family Therapy, 34(1), 11-28. doi:10.1007/s10591-011-9170-6

Potter, J. (2003). Discursive psychology: Between method and paradigm. Discourse \& Society, 14(6), 783-794. doi:10.1177/09579265030146005

Potter, J. (2012). Discursive psychology and discourse analysis. In J. P. Gee, \& M. Handford (Eds.), The Routledge handbook of discourse analysis (pp. 104-119). London: Routledge.

Ramseyer, F., \& Tschacher, W. (2011). Nonverbal synchrony in psychotherapy: Coordinated body movement reflects relationship quality and outcome. Journal of Consulting and Clinical Psychology, 79, 284-295. doi:10.1037/a0023419

Rober, P. (2015). The challenge of creating dialogical space for both partners in couple therapy. Australian and New Zealand Journal of Family Therapy, 36, 105-121. doi:10.1002/anzf.1090

Råkil, M. (2006). Are men who use violence against their partners and children good enough fathers? The need for an integrated child perspective in the treatment work with the men. In C. Humphries \& N. Stanley (Eds.), Domestic violence and child protection (pp. 190-202). London, England: Jessica Kingsley.

Sarbin, T. R. (1986). The narrative as a root metaphor for psychology. In T. R. Sarbin (Ed.), Narrative psychology. The storied nature of human conduct (pp. 3-21). New York: Praeger.

Schore, A. N. (2001). Minds in the making: attachment, the self-organizing brain, and developmentally-oriented psychoanalytic psychotherapy. British Journal of Psychotherapy, 17(3), 299-328. doi:10.1111/j.1752-0118.2001.tb00593.x 
Schore, J. R., \& Schore, A. N. (2008). Modern attachment theory: The central role of affect regulation in development and treatment. Clinical Social Work Journal, 36(1), 9-20. doi:10.1007/s10615-007-0111-7

Seikkula, J., Karvonen, A., Kykyri, V. L., Kaartinen, J., \& Penttonen, M. (2015). The embodied attunement of therapists and a couple within dialogical psychotherapy: An introduction to the relational mind research project. Family Process, 54, 703-715. doi:10.1111/famp.12152.

Stancombe, J., \& White, S. (2005). Cause and responsibility: Towards an interactional understanding of blaming and 'neutrality' in family therapy. Journal of Family Therapy, 27, 330-351. doi:10.1111/j.1467-6427.2005.00326.x

Stratton, P. (2003). Causal attributions during therapy I: Responsibility and blame. Journal of Family Therapy, 25, 136-160. doi:10.1111/1467-6427.00241

Vall, B., Seikkula, J., Laitila, A., \& Holma, J. (2016). Dominance and dialogue in couple therapy for psychological intimate partner violence. Contemporary Family Therapy, 38(2), 223-232. doi:10.1007/s10591-015-9367-1

Vall, B., Seikkula, J., Laitila, A., Holma, J., \& Botella, L. (2014). Increasing responsibility, safety, and trust through a dialogical approach: A case study in couple therapy for psychological abusive behavior. Journal of Family Psychotherapy, 25, 275-299. doi:10.1080/08975353.2014.977672

Veteläinen, A., Grönholm, H., \& Holma, J. (2013). Discussions of fatherhood in male batterer treatment group. Sage Open, 3(2). doi:10.1177/2158244013492083

Wetherell, M. (1998). Positioning and interpretative repertoires: Conversation analysis and poststructuralism in dialogue. Discourse \& Society, 9(3): 387-412. doi:10.1177/0957926598009003005 
Wolfe, D. A., Crooks, C. V., Lee, V., McIntyre-Smith, A., \& Jaffe, P. G. (2003). The effects of children's exposure to domestic violence: A meta-analysis and critique. Clinical Child and Family Psychology Review, 6(3), 171-187. doi:10.1023/A:1024910416164 